\title{
Bridging Strength, Monotonicity, and Word Order Choices in Catalan
}

\author{
Lisa Brunetti ${ }^{\mathrm{a}}$
}

Laia Mayol ${ }^{\mathrm{b}}$

and Xavier Villalba ${ }^{\mathrm{c}}$

${ }^{a}$ CNRS \& Université de Paris, Paris, France; ${ }^{b}$ Universitat Pompeu Fabra, Barcelona,

Catalonia (Spain); ' Universitat Autònoma de Barcelona, Cerdanyola del Vallès, Catalonia (Spain)

\section{ARTICLE HISTORY}

Compiled November 13, 2020

\begin{abstract}
Three experimental studies are presented testing the choice of a left or a right dislocation in Catalan, depending on the bridging relation between the dislocate and its antecedent. We make the hypothesis that the stronger the anaphoric link between the dislocate and its antecedent, the more appropriate a right dislocation is, while the opposite is true for left dislocation. The results of two acceptability judgment experiments partially support our hypothesis: Ratings with right dislocation decrease proportionally to the strength of the anaphoric link; however, it is ratings of canonical sentences (without dislocation at all), rather than of left dislocation, that display the opposite direction. For left dislocation, the picture is more complex and reflects the pragmatic function of this construction as a topic shifter or marker of contrast. A third experiment tests the monotonicity hypothesis, according to which a left dislocation is chosen when the anaphoric relation with the antecedent is either downward monotonic or non-monotonic, while a right dislocation is preferred with an upward monotonic relation. The results partially support such hypothesis, but they also further support the importance of taking the pragmatic function of left dislocation into account to explain its choice in discourse by speakers.
\end{abstract}

CONTACT Lisa Brunetti. Email: lisa.brunetti@linguist.univ-paris-diderot.fr 


\section{KEYWORDS}

Bridging, anaphora, left dislocation, right dislocation, Catalan

\section{Introduction}

The interpretation of utterances is sensitive to the way we phrase them in a particular context. For example, whereas the sentence in (1a) can be an appropriate answer to Sally's question, (1b) cannot, which we mark by means of \#, as is standard practice:

(1) Sally: What did Mary bring to the party?

a. Heather: Mary brought the cookies.

b. Heather: \#The cookies were brought by Mary.

The form of (1a) matches the way we place informative elements in the sentence: The element carrying new information (the cookies) appears at the end of the sentence, where it receives the main stress, and the element encoding old information and the topic of the sentence (Mary) is in the initial subject position. Hence, the utterance conforms to the common old-new articulation of most sentences, also labeled theme-rheme or topic-comment. In contrast, even though (1b) includes the relevant information to answer Sally's question, in Heather's answer there is a mismatch between the position of the elements and their information status: The phrase the cookies is new information, but it is placed in initial position -where old information is expected- and Mary is old information, but it is placed in final position -where new information is expected.

In the literature, the fit between the position of the different constituents of a sentence and their informative value has been studied at length from many perspectives under the label of functional sentence perspective (Daneš, 1974; Firbas, 1992), information packaging (Chafe, 1976; Vallduví, 1992) or information structure (Lambrecht, 1996; Ward \& Birner, 2008a, 2008b). In this article we study a syntactic construction that offers a transparent encoding of information structure: dislocation.

\section{Left and Right Dislocation}

A dislocation places the constituent carrying old information in a peripheral, extrasentential position, either to the left (my iguana Bingo in (2)) or to the right (that 
Van Gogh in (3)); the dislocate is separated from the clause by a comma, and it is represented within the sentence by means of a pronoun:

(2) Speaker A: Tell him about Bingo. Tell him about your iguana.

Speaker B: My iguana Bingo, he almost bit my finger off. (South Philadelphia Corpus, cited in Manetta, 2007, p. 1032)

(3) I just saw the newly discovered Van Gogh painting at the Art Institute; apparently he painted it when he was only 11 years old. He was a genius, that Van Gogh. (Birner \& Ward, 1998, p. 149)

As several authors (Forcadell, 2016; Mayol, 2007; Vallduví, 1992) highlight, dislocation in English is not particularly common, since this language mainly resorts to prosodic means to encode different informative values. This fact makes English utterances less transparent in the syntactic encoding of information structure, which renders experimental testing more difficult. Henceforth, we are studying dislocations in Catalan, a Romance language which offers a transparent syntactic encoding of old information in a highly productive way: Constituents carrying old information (topics) must be dislocated outside the core of the sentence. This allows the element carrying new information to receive the main stress in its final sentence position (the verb puc sofrir 'can stand' in (4) and the verb odia 'hates' in (5)), as in the following Catalan examples (from now on, we will just consider Catalan data, sometimes in contrast with English):

(4) a. M'agrada molt aquest barri.

'I like this neighborhood very much.'

b. Però els veïns, no els puc sofrir. but the neighbors not them can suffer 'But the neighbors, I can't stand them.'

(5) a. Per què li vas portar un pastís a la Maria?

'Why did you bring a cake to Maria?'

b. Els odia, els pastissos. the hates the cakes 'She HATES cakes.' 
Note that the pronoun in Catalan dislocations is a prosodically weak form ( $\mathrm{els}$ 'them') attached to the verb (what the linguistic literature calls a clitic pronoun, hence the name of clitic left/right dislocation assigned to these constructions in Romance linguistics).

While both left and right dislocation mark constituents carrying old information, they are not equivalent from an informative point of view. It is a well-established fact that left dislocation is used to introduce a new sentence topic (Brunetti, 2009a,b; Prince, 1998; Vallduví, 1992; Villalba, 2000), in many cases making a contrast with the previous one (Arregi, 2014; Brunetti, 2006, 2009a). As the English translation shows, the most typical English construction for such; contrastive cases is topicalization (namely left detachment without pronoun resumption):

(6) El llibre ja l'he llegit, però la revista encara no l'he the book already it-have read but the magazine yet not it-have acabada.

finished

'The book, I have read already, but the magazine, I haven't finished yet.'

Many works on different languages make the claim that left dislocation triggers contrast, but accounts differ on whether contrast has to be considered as an inherent semantic property of this construction (Arregi, 2014; López, 2009), or rather as a conversational implicature (Tomioka, 2010; Vallduví, 1992). According to the second view, which we adopt, the contrastive interpretation of left dislocation follows from its function as a new (shifted) topic. Indeed, as discussed by Bott (2007) and Brunetti (2006, 2009a), when a new topic is introduced into discourse, it is naturally inferred to be in contrast with the preceding topic. Moreover, in many cases, the new topic can be picked up from a salient set of possible topics: The presence of a set of alternatives favors thus an interpretation where the left dislocate is in contrast with such alternatives. All in all, left dislocation is typically interpreted as contrastive, with important consequences that we will comment on in Section General Discussion and Conclusions.

On the contrary, right dislocates encode background (old) information, and more precisely old information which is not active, but needs to be reactivated for discourse purposes. Consider for instance the following example from a theater play, in which 
Xeixa is seen sifting wheat (Villalba \& Mayol, 2013, p. 97):

(7) Xeixa: Tant se me'n dóna que quedi net com brut, aquest Xeixa: so myself to-me-of.it matters that gets clean as dirty this blat.

wheat

"Xeixa: What does it matter whether the wheat's clean or whether it ain't clean?"

Here, the wheat is part of the background, since it is present in the extralinguistic context; however, it is not active, since it was not explicitly mentioned before the utterance. In this context, right dislocation makes this information accessible for discourse reference.

While left and right dislocation have different functions, there is consensus that dislocates cannot encode information which is new to the speaker and must, thus, be anaphorically related to an accessible antecedent in the context. For example, the left dislocate els veïns 'the neighbors' in (4) is anaphoric to aquest barri 'this neighborhood' and the right dislocate els pastissos 'the cakes' in (5) is anaphoric to un pastís 'a cake'.

There is, however, debate on the exact nature of the anaphoric relation between dislocates and their antecedents and on the constraints regulating it. This is unsurprising, for the mechanism by which a link is established between a referent of an expression and some other referent in previous discourse is based on linguistic and extralinguistic knowledge and can be analyzed from different scientific perspectives. ${ }^{1}$ In the next section, we consider the most important proposals in the linguistic tradition.

\section{Anaphoric Relations of Dislocates}

\section{Partially ordered sets.}

An influential proposal on the type of anaphoric relation between the dislocate and its antecedent is that dislocates must be related to their antecedents by means of a partially ordered set (poset) relation ${ }^{2}$ (Vallduví, 1992). This hypothesis was originally designed to define the relation between topicalized phrases and their antecedents in

\footnotetext{
${ }^{1}$ The study of anaphoric reference in discourse has been a major issue in theoretical linguistics (Huang 2000; Reinhart, 1983), discourse analysis (Schwarz-Friesel, 2007; Webber et al., 2003), natural language processing (Mitkov, 2012; Poesio, 2016), psycholinguistics (Haviland \& Clark, 1974; Singer, 2012), and neurolinguistics (Burkhardt, 2006; Callahan, 2008).

${ }^{2} \mathrm{~A}$ poset is a set defined by a relation that is either reflexive, antisymmetric and transitive or irreflexive, asymmetric, and transitive. See Partee, ter Meulen and Wall (1987, pp. 277-280), for technical details.
} 
English (Ward \& Prince, 1991). Typical cases of poset relations are the part-of and the subset relations, which are expected to be fine for left dislocates, as shown in (8):

(8) a. Aquesta casa és preciosa, però les finestres, les han fet petites. this house is precious, but the windows them have made small

'This house is lovely, but the windows were built small.'

b. Menjo molta fruita, però el mango, no el suporto. eat much fruit but the mango not him stand 'I eat a lot of fruit, but mangoes, I cannot stand.'

However, the poset account has to face a problematic case: inferable relations (Hendriks, 1996; Hendriks \& Dekker, 1995), which are not poset relations, but do allow left dislocations. Observe the following dialogue, from Villalba (2000, ch. 2):

(9) a. M'agrada molt aquesta casa.

'I like this house very much.'

b. A l'arquitecte, en canvi, no el va satisfer el resultat. to the architect in change not it did satisfy the result 'The architect, however, wasn't satisfied with the result.'

The relation between a house (the antecedent) and its architect (the left dislocate) cannot be formalized as a poset, yet the dislocation is totally acceptable.

The poset analysis is also unsatisfactory when we consider right dislocation, for only a small group of poset relations are possible here. As Birner and Ward (1998, p. 149) point out, identity, which is a poset relation, is prototypical for right dislocation, as in the example in (5) above, where we have a cake as the antecedent of the dislocate the cakes. However, we have clear poset relations, such as the whole-part relation, which are unfelicitous with right dislocations -though fine with left dislocations, cf. (8-a):

(10) *Aquesta casa és preciosa, però les han fetes petites, les finestres. this house is precious, but them have made small the windows 'This house is lovely, but the windows were built small.'

Moreover, as pointed out in Ziv (1994, fn. 27), non-poset relations set apart left and right dislocations. In example (11), a non-poset relation (bus-driver) is possible with a left dislocation (11-a), but not with a right dislocation (11-b): 
(11) He agafat l'autobús aquest matí.

'I went on a bus this morning.'

a. Al conductor, l'havien apallissat.

'The driver, he had been beaten hard.'

b. \#L'havien apallissat, al conductor.

'He had been beaten hard, the driver.'

Notwithstanding, counterexamples can be found of non-poset cases (work-author) with right-dislocation, in Catalan (12a) and even in English (12b):

a. No sé com pots llegir Washington Square. Jo no el suporto, a Henry James.

'I don't know you can read Washington Square. I can't stand him, Henry James.'

b. I saw Modern Times again yesterday. He's amazing, (this) Charlie Chaplin. (Grosz \& Ziv, 1998, example 20)

To sum up, posets do not correctly describe the relation between dislocates and their discourse antecedents: We fall short of explaining the availability of left dislocates (and some right dislocates) with non-poset relations (i.e. house-architect); in addition, we cannot explain why right dislocates are mostly restricted to the subclass of poset relations involving identity.

\section{Monotonicity}

To overcome the limitations of the poset analysis, Bott (2007) argues for an approach based on monotonicity, which regulates inference patterns between sets or between parts and wholes. For example, we have an upward monotonic relation when we move from a subset (citrus) to its superset (fruit) or from a part (window) to its whole (house). When we reverse the relation, we obtain a downward monotonic relation. When relations are not between sets nor between parts and wholes (e.g. houses and architects), we have non-monotonic relations.

Following previous work by Alexopoulou and Kolliakou (2002), Hendriks (1996), and Hendriks and Dekker (1995), Bott argues that non-monotonic anaphors are always 
associated to left dislocates - recall examples (9) and (11)- but he crucially claims that when monotonic anaphors are involved, a clear distribution exists between dislocation types: Downward monotonic ones associate with left dislocates (13), whereas upwardmonotonic ones with right dislocates (14) (examples adapted from Bott, 2007):

Q: Which relationship did Bach have to string instruments?

A': La viola, segur que li va agradar. the viola, sure that to-him did please

'The viola, he surely liked.'

A"\#Segur que li va agradar, la viola.

'He surely LIKED the viola.'

Q: Which relationship did Bach have to the viola?

A': Segur que li van agradar, els instruments de corda. sure that to-him did please, the instruments of string

'He surely LIKED string instruments.'

A"\#Els instruments de corda, segur que li van agradar.

'String instruments, he surely liked.'

In (13), we are dealing with a downward monotonic relation: We move down from the general antecedent string instruments to the specific dislocate violas. Hence, only left dislocates are felicitous. In (14), we are dealing with the reverse situation, namely an upward monotonic relation: We move up from the specific antecedent violas to the general dislocate string instruments. In this case, only right dislocates are felicitous, according to Bott.

In sum, even though Bott's monotonicity hypothesis is clearly superior to the poset hypothesis in offering a principled explanation of the restricted set of relations available for right dislocation in comparison to left dislocation, it still falls short. First, it predicts that left and right dislocation should be in complementary distribution, namely that they cannot be possible in the same context. We will see that this prediction is not fulfilled. Second, it cannot explain clear-cut cases of non-monotonic right dislocation like (12): I saw Modern Times again yesterday. He's amazing, (this) Charlie Chaplin. Finally, Bott must reduce the case of non-monotonic anaphoric relations 
(e.g. the house-architect case) to a subspecies of part-whole relations, hence to cases of downward anaphora, which is at least dubious on theoretical grounds.

\section{Bridging}

The previous proposals based on posets or monotonicity point to the fact that right dislocations are mostly restricted to identity relations with a discourse antecedent, whereas left dislocations have a wider choice. This intuition pervades the relevant literature (Birner \& Ward, 1998; Brunetti, 2009a; Grosz \& Ziv, 1998; Vallduví, 1992; Villalba, 2000; Villalba \& Mayol, 2013; Ziv, 1994), but we still don’t have a complete picture of such relations and how they affect the position of dislocates, nor experimental support for the hypotheses. We think that this can be achieved if we consider the anaphoric relationship between the dislocate and its antecedent described in this section through the lenses of the better studied concept of bridging.

Bridging is conceived by Clark (1975) as a type of inference, which is necessary to accommodate particular given-new structures (for developments, see Asher, 1998; Geurts, 2011; Irmer, 2011; Matsui, 1998, 2000; Umbach, 2003). Consider the following pair of examples:
a. John saw someone leaving the party early. It was Mary who left.
b. In the group there was one person missing. It was Mary who left.

In (15-a) below we are simply fulfilling the missing identity of the person leaving, so we move from "X left" to "Mary left". In contrast, in (15-b), the listener must build the intermediate step (a bridge) "X left" between "X was missing" to "Mary left". That is, she must make the reasonable inference that the person was missing because she had left. Since this a reasonable inference, it must resort not only on discourse, but also on world knowledge, just as happens with conversational implicatures (Grice, 1975).

Clark discusses several types of bridging relationships, which we summarize as follows:

a) Direct reference: The anaphora makes direct reference to something just mentioned. It involves three subclasses: 
i) Identity: "I met a man yesterday. The man told me a story."

ii) Epithets: "I met a man yesterday. The bastard stole all my money."

iii) Set-member: "I met two doctors yesterday. The tall one told me a story."

b) Indirect reference by association: There is no explicitly mentioned antecedent, but it is a part of something that has been mentioned.

i) Necessary part: "I looked into the room. The ceiling was very high."

ii) Inducible part: "I walked into the room. The chandeliers sparkled brightly."

c) Indirect reference by characterization: The antecedent plays an implicit role in an event or circumstance explicitly mentioned.

i) Necessary role: "John was murdered yesterday. The murderer got away."

ii) Optional role: "John died yesterday. The murderer got away."

d) Reasons, Causes, Consequences or Concurrences: All relations where the antecedent is an event. For instance, in the utterance "John fell; what he wanted to do was scare Mary", the fact that John wanted to scare Mary is the reason for John's falling.

Note that, whereas (a) and (b) involve standard cases of nominal anaphora, in types (c) and (d), the antecedent is not an entity, but an event. Since event anaphora are subject to particular constraints (see Asher, 2000; Singer \& Halldorson, 1996) for discussion), in the current work we will focus on nominal anaphora only and, thus, on the direct reference and indirect reference by association types.

While other classifications of bridging types exist (e.g. Gardent, Manuélian, \& Kow, 2003; Kleiber, 2001; Schwarz-Friesel, 2007), all classifications entail a scale of referential strength: Direct reference cases (e.g. identity) build stronger bridges than indirect cases (e.g. necessary role), and necessary part/role build stronger bridges than optional or probable ones. We will build on this idea to experimentally test the sensitivity of left and right dislocation to referential strength, as will be described in the next section.

\section{Testing Bridging and Dislocation}

In designing the experimental procedure (all experimental material is available at the OSF repository: https://osf.io/73bvq) our general goal was to test the bridging strength hypothesis, namely the idea that the strength of the anaphoric link between 
the antecedent and the dislocate has an impact on the preference for either left or right dislocation. Given the pragmatic properties of dislocations described in Section Left and Right Dislocation, some relations between these dislocation types and different bridging types clearly emerge. On the one hand, right dislocation typically recovers some referent that is not active anymore in the discourse or provides some additional property to a previously mentioned referent, as in the case of epithets. Henceforth, a right dislocation will generally be associated with bridging types involving identical antecedents. On the other hand, left dislocation mainly has a topic shifting or a contrastive function, encoding an explicit or implicit referent: In both cases, a set of at least two alternatives will be available in the immediately preceding discourse. As a consequence, we expected left dislocation to be associated with bridging types involving weaker anaphoric relations. Such hypothesis was tested in the first two experiments.

In Bott's (2007) monotonicity hypothesis (see Section Monotonicity), right dislocation is preferred with upward monotonic relations -namely a relation which goes from a more specific antecedent to a more general dislocate-, whereas left dislocation is preferred with downward monotonic relations -namely a relation which goes from a more general antecedent to a more specific dislocate. Since upward anaphora involves entailment (talking about violas entails talking about string instruments), it is a stronger condition than downward anaphora, which does not (talking about string instruments does not entail talking about violas). We can thus suggest that the stronger (upward) monotonicity relation correlates with the stronger bridging types, and the weaker (downward) monotonicity relation, with the weaker ones. The third experiment tested this hypothesis.

\section{Experiment 1}

The research question behind the first experiment was what preferences Catalan speakers had with respect to the position of the dislocate in contexts involving the following five bridging relations: (a) epithet, (b) hypernym, (c) set-member (direct reference relations, see Section Bridging), (d) necessary part, and (e) optional part (indirect reference by association). An example of experimental item per each bridging type is given below, with a right dislocation in (a) and a left dislocation in (b). Note 
that all variants are given without acceptability judgments; as the experiments will show, they are not all equally acceptable.

(16) 'Yesterday, on the street, I saw Andreu, our former accountant.' [epithet]
a. El vaig evitar, aquell desgraciat. him I.did avoid that wretch 'I avoided that wretch.'

b. Aquell desgraciat, el vaig evitar.

(17) 'Mary cooked chickpeas.' [hypernym]
a. No els suporto, els llegums. not them I.stand the legumes
'I cannot stand legumes.'

b. Els llegums, no els suporto.

(18) 'Last summer, I visited the cities of Tuscany.' [set-member]
a. La vaig recórrer de punta a punta, Florència. it I.did go.through from end to end Florence 'I wandered all through Florence.'

b. Florència, la vaig recórrer de punta a punta.

(19) 'My parents gifted me with a new laptop.' [necessary part]
a. La té tàctil, la pantalla.
it has tactile the display
'It has a touch display.'

b. La pantalla, la té tàctil.

\section{'I recommend this hotel.' [optional part]}
a. L' havien reformada, la piscina.
it they.had renovated the swimming-pool
'The swimming-pool had been renovated'

b. La piscina, l'havien reformada.

The bridging strength between the referent of the dislocate and its antecedent decreases from epithet to optional part in the following manner:

$$
\text { epithet }>\text { hypernym }>\text { set-member }>\text { necessary part }>\text { optional part }
$$


Following Clark $(1975,1977)$, we motivate this order as follows. First, the antecedent is semantically closer with direct reference than with indirect reference. In other words, the implicature triggered by direct reference is simpler than the one triggered by indirect reference, which results in faster processing, as originally reported in Haviland and Clark (1974). As for the order of the three bridging types involving direct reference, it is motivated by the following considerations. When the bridging relation involves an epithet, like in (16), the referent denoted by the antecedent and the one denoted by the dislocate are the same: What changes is just the linguistic expression used to refer to it. In a case of hypernymy -cf. (17)- the second utterance still predicates about chickpeas, but it does so indirectly by talking about legumes in general, namely about the kind of which chickpeas are a token. Finally, within a set-member bridging relation like (18), the second utterance does not predicate about the antecedent at all (the cities of Tuscany) but only about one specific city of Tuscany (Florence), hence the predication does not necessary hold for the other cities. As for the order of necessary part before optional part within indirect reference, the assumption is simply that talking about a necessary part is closer to talking about the whole than when one does it of some part that is not essential to identify the whole.

Recall that the bridging relations we took into account were not exhaustive of the bridging possibilities described by Clark and subsequent work. As a matter of fact, constraints in the experimental setup and in the statistical analysis led us to choose only one part of the scale of bridging strength. In particular, as mentioned in Section Bridging, we excluded bridging types involving event anaphora.

The specific hypotheses we made for this experiment were the following:

The bridging strength hypothesis: Dislocation structures are sensitive to the anaphoric strength according to a bridging scale in the following way:

(a) The more "anaphorically strong" the relationship between a right dislocate and its antecedent, the better; and (b) the more "anaphorically weak" the relationship between a left dislocate and its antecedent, the better.

Hence, we predicted that ratings of sentences with right dislocation would be optimal with epithets and that they would decrease as the anaphoric link becomes weaker, up to 
the optional part bridging type, which would render the worst ratings. In contrast, for a sentence with left dislocation, the hypothesis is reversed: We expected the sentence to be preferred when the bridging link was less strong. In other words, the ratings of left and right were expected to peak at opposite ends of the scale of bridging possibilities.

Method.

Participants.

Sixty-seven native Catalan speakers participated in Experiment 1; they were university students at the Universitat Autònoma de Barcelona and at the Universitat Pompeu Fabra, in Barcelona. All participants answered a version of the Bilingual Linguistic Profile (Gertken, Amengual \& Birdsong, 2014), adapted to Catalonia's situation, and 20 candidates were discarded because they were classified as Spanish language dominant speakers. The participants we eventually considered were 47 (38 female and 9 male), aged 17-51 (mean age: 22.1).

\section{Design.}

Experiment 1 included 30 experimental items, 6 for each of the 5 tested bridging types (epithet, hypernym, set-member, necessary part, and optional part). Each item had a context sentence containing the antecedent, followed by either a left or a right dislocation of a definite direct object nominal expression, and for each item, the participant only saw one of the two constructions. We controlled for the grammatical function of the antecedent. Indeed, it is well-known that the syntactic position of the antecedent makes the latter more or less anaphorically accessible from the dislocate (Ariel, 2001; de la Fuente et al. 2016; Kaiser \& Trueswell, 2008). In particular, it has been claimed that a preverbal subject, because of its tendency to be the topic of the sentence, is preferred in various languages as the antecedent of a pronoun in a subsequent utterance, for concerns of topic continuity (de la Fuente et al. 2016; Givón, 1983). We therefore decided to present participants with two types of context sentences: one where the antecedent of the dislocate was a postverbal object, cf. el nou Mac in (23-a), and one where it was a preverbal subject, cf. el nou Mac in (23-b).

a. Els pares m'han regalat el nou Mac. the parents to.me.have given the new Mac 'My parents gave me the new Mac (as a present).' 
b. El nou Mac és molt eficient.

the new Mac is very efficient.

'The new Mac is very efficient.'

c. La pots apagar amb la veu, la pantalla.

it you.can turn.off with the voice, the screen

'You can turn off the screen with your voice.'

Items were presented both in oral and in written form, and the experiment used a Latin Square design.

\section{Procedure.}

Participants had to give an acceptability judgment using a 10-point Likert scale ${ }^{3}$. Before doing that, they had to read the instructions and were tested for language dominance. Then, participants also had to rate three practice items. Only then, they could start the actual experimental task. The data was collected using the web interface Ibex Farm (http://spellout.net/ibexfarm, Drummond, 2016).

\section{Results}

A statistical analysis based on a linear mixed-effect model, using R (R Core Team, 2018) and lmerTest (Bates et al., 2015), was carried out on the data (see the R-coding at the OSF repository: https://osf.io/73bvq). Participants' ratings were used as the dependent numerical variable. The independent variables (all categorical) were: (a) dislocation type, (b) grammatical function (of the antecedent), and (c) bridging type. Dislocation type had two conditions: left and right, the latter being coded as reference category. Grammatical function had two conditions too: The antecedent was either the grammatical subject (coded as the reference category) or an object. Finally, bridging type had five conditions: (a) epithet, (b) hypernym, (c) set-member, (d) necessary part, and (e) optional part. Since we hypothesized a gradual change of the ratings assigned to right and left dislocations from the strongest to the weakest bridging link between the dislocate and the antecedent, bridging types were coded using Helmert contrasts (Vasishth \& Broe, 2011; Venables \& Ripley, 2013, pp. 149-209), and ordered in the model from the anaphorically strongest to the anaphorically weakest, as indicated in (21). ${ }^{4}$ Participant and item were taken as random factors.

\footnotetext{
${ }^{3}$ The choice of such a scale is motivated by the participants' (mostly university students) familiarity with a 10 -point scale, which is used in Catalonia for evaluation at school and at the university.

${ }^{4} \mathrm{~A}$ Helmert contrast coding compares the mean scores of each condition with the mean scores of the totality
} 
The means (and standard errors) for right and left dislocation both globally and for each bridging type are given in Table 1. [TABLE 1]

The statistical analysis showed an overall preference for left over right dislocation, $b=0.40, S E=0.11, t(1326)=3.45, p<.001$. As shown by Figure 1, left dislocation was preferred to its right counterpart in 3 of the 5 bridging types.

\section{[FIGURE 1]}

As for the interaction between dislocation and grammatical function, no significant effect was obtained, $b=0.08, S E=0.11, t(1326.10)=0.68, p=.50$, so our results did not provide evidence for an effect of the grammatical function of the antecedent (subject or object) on dislocation preferences.

An interaction was found between bridging type and dislocation type. Taking into account such an interaction significantly improved the model, as shown by the results of a likelihood ratio test between a model with and a model without the interaction, $\chi^{2}(4)=50.13, p<.001$. Results partially support our bridging strength hypothesis: Ratings gradually decreased with right dislocation, though they did not always increase with left dislocation (see Figure 1). Means (and standard errors) of combinations of bridging types are given in Table 2. More precisely:

- Ratings decreased with right dislocation from epithet + hypernym to set-member and increased with left dislocation, $b=0.62, S E=0.10, t(1326)=5.90, p<$ .001 .

- Ratings also decreased with right dislocation from epithet + hypernym + setmember to necessary part, $b=0.26, S E=0.07, t(1326)=3.49, p<.001$, but with left dislocation, they did not differ significantly at this point.

- Ratings kept decreasing with right dislocation from epithet + hypernym + setmember + necessary part to optional part, but unexpectedly, the same was true with left dislocation; nevertheless, the difference was significantly greater with right than with left dislocation, $b=0.12, S E=0.06, t(1326)=2.04, p=.042$.

[Table 2]

of the preceding conditions. Given the order of the five bridging conditions in the model, the mean score of set-member was compared with the mean scores of epithet + hypernym; the mean score of necessary part was compared with the mean scores of epithet + hypernym + set-member, and so on. 


\section{Discussion}

The bridging strength hypothesis is supported by Experiment 1, but only partially. Ratings of sentences with a right dislocate decrease from epithet to optional part; ${ }^{5}$ however, with a left dislocate, ratings do not keep increasing from epithet to optional part: They do rise up to set-member, but then they decrease from set-member to optional part. As Figure 1 shows, there seems to be a split between the first two bridging types on one side and the other three on the other: In the former group, scores are higher for right dislocation, while in the latter, scores are higher for left dislocation. How can this pattern be explained? We believe that an explanation must be searched in factors other than bridging strength. As discussed in Section Left and Right Dislocation above, a clear association is made in the literature between a position of the dislocate in the left periphery and the fact that the referent of the dislocate is picked up from (and sometimes opposed to) a set of alternatives, which is present in or inferable from the discourse context (Bott, 2007; Brunetti, 2009a; Mayol \& Villalba, 2018; Vallduví, 1992). The interesting point for us is that depending on the bridging type, such an alternative set may be more or less easily reconstructed. Among our five bridging types, those that favor such an interpretation are precisely the last three: set-member, necessary part, and optional part. With set-member, the dislocate is a member of a set of alternatives by definition; with necessary and optional parts, the different parts of the whole represent the alternatives to the dislocate (though with optional part, the alternatives may be less easy to infer). Our results interestingly show that it is precisely these bridging types that receive higher ratings with left dislocation.

Going back to the bridging strength hypothesis formulated in (22), in conclusion our results do not support the second part of it, namely that left dislocation is preferred when the bridging link is weaker. In other words, our results do not say anything about the syntactic preferences of a definite expression when the bridging link with its antecedent is weak. By focusing on dislocations, however, in Experiment 1 we did not take into account cases where the definite expression occupies a non-dislocated, in situ position, such as Florència in (24). Experiment 2 provides a more complete picture by also testing canonical sentences (that is, sentences without dislocations).

\footnotetext{
${ }^{5}$ Though no significant difference from epithet to hypernym is found.
} 

a. Vaig recórrer Florència de punta a punta.
I.did go-through Florence from end to end
'I wandered all through Florence.'

Before presenting Experiment 2, we would like to briefly comment on the absence of a significant effect of grammatical function on dislocation preferences. This result may be due to the difference between a full nominal expression and a pronoun, which prevents us from making a full comparison of our results with those provided by de la Fuente et al. (2016). However, the result might also simply be due to the type of stimuli presented to our informants. Consider again (23), repeated here for ease of reference:
a. Els pares m'han regalat el nou Mac.
'My parents gave me the new Mac (as a present).'
b. El nou Mac és molt eficient.
'The new Mac is very efficient.'
c. La pots apagar amb la veu, la pantalla.
'You can turn off the screen with your voice.'

Since the context-sentence ( $\mathrm{a}$ or $\mathrm{b}$ ) is the only context preceding the dislocation, the reader/listener unconsciously interprets it as the starting point of the discourse. It is rather natural to imagine that el nou Mac 'the new Mac' is going to be the new topic of subsequent discourse. Therefore, the retrieval of the antecedent for $l a$ pantalla 'the screen' does not seem to be a problem in either context. Note furthermore that el nou Mac is the only referent that can entertain a bridging relation with $l a$ pantalla 'the screen': In (23a), it is the only referent present, and in (23b), the sentence contains another referent, els pares 'the parents', but such a referent clearly cannot entertain any bridging relation with the screen. Finally, it must be added that the context sentence of our stimuli was particularly short, so this may be why the syntactic position of the antecedent had a less strong effect than in the stimuli of the experiments presented in the literature. 


\section{Experiment 2}

In this experiment we added canonical sentences to the comparison, and assumed that canonical sentences contained only new information, so the target expression (the one corresponding to the dislocate in the non-canonical constructions) was new information too. ${ }^{6}$ Note that the target expression was a definite one, so like the dislocate, it required an antecedent in order for the second utterance to be a coherent continuation. For instance, in example (24), where the target expression Florència 'Florence' refers to one of the cities of Tuscany mentioned in the context sentence, a rhetorical relation can be identified between the two utterances (an Elaboration): The speaker gives more particulars about the event described in her first utterance (Kehler, 2002). If, say, París 'Paris' replaced Florència, no clear relation between the two utterances would subsist. ${ }^{7}$ Since the target expression is new information, we expect the anaphoric link with its antecedent to be weak. As a matter of fact, the stronger the anaphoric link, the more easily recoverable the referent is, and therefore, it is less plausible that it conveys new information.

What difference do we expect between a canonical sentence and a left dislocation? Since the latter is a more marked construction, we expect it to be preferred in contexts where some particular pragmatic function is required, which a left dislocation but not a canonical sentence may be able to express. Summing up, the bridging strength hypothesis of Experiment 1 is reformulated in Experiment 2 as follows:

- For dislocations, we predict the same as in the previous experiments.

- We expect canonical sentences to be preferred when the bridging strength is weaker.

\section{Method.}

Participants.

Eighty-one native Catalan speakers took part in Experiment 2 on Ibex Farm. They were mostly students at the Universitat Autònoma de Barcelona and at the Universitat

\footnotetext{
${ }^{6}$ We did not control for the relative informativeness of the object with respect to other material in the same sentence, which may vary from item to item. However, since we included items as a random factor in the statistical analysis, this potential variation was controlled by the model.

${ }^{7}$ In our experiment, the rhetorical relation between the two utterances is always either an Elaboration or a Comment. On rhetorical relations, see Mann and Thompson (1988) and Asher (2003).
} 
Pompeu Fabra; they had not participated in Experiment 1. All participants answered a questionnaire on their linguistic profile (the same used in Experiment 1), and we discarded 11 candidates who were classified as Spanish language dominant speakers. The data were therefore collected from a total of 70 participants (57 women and 13 men) aged 18-67 (mean age: 23,4).

\section{Design.}

Exactly like Experiment 1, Experiment 2 included 6 items per each of the 5 tested bridging types (epithet, hypernym, set-member, necessary part and optional part). Each item came in three forms: a context-sentence was followed by either a left dislocation, or by a right dislocation, or by a canonical sentence. Twenty-one fillers were added.

The bridging types and the experimental setup of this experiment were the same as those in Experiment 1, except for the addition of canonical sentences, see example (24). Also, since the grammatical function of the antecedent played no role in Experiment 1 , we restricted antecedents to postverbal objects only.

Procedure.

The same procedure was followed as in Experiment 1.

\section{Results}

A statistical analysis based on a linear mixed-effect model was carried out as in Experiment 1, with ratings as dependent variable and participant and item as random factors. The independent variable bridging type was the same as in Experiment 1, and was also coded using Helmert contrasts, with the order of conditions as in (21). The other independent variable, construction type, had three conditions: right dislocation (coded as reference category), left dislocation, and canonical sentence.

The mean ratings (and SE) of the three constructions globally and for each bridging type are presented in Table 3.

\section{[TABLE 3]}

Results showed significantly higher ratings for left over right dislocation across all bridging types, $b=-0.47, S E=0.13, t(1868.50)=-3.68, p<.001$, while no significant difference was found between left dislocation and canonical sentences, $b=0.23, S E=$ $0.13, t(1868.80)=1.78, p=.075$. 
An interaction between construction type and bridging type was supported by a comparison via a likelihood ratio test of a model with and a model without the interaction: Results showed that the model is significantly improved by the presence of such interaction, $\chi^{2}(8)=78.73, p<.001$. As in Experiment 1, ratings gradually decreased with right dislocation, but they did not gradually increase with left dislocation; they did however increase with canonical sentences, as illustrated in Figure 2.

\section{[FIGURE 2]}

More specifically, we observed the following (see Table 4 for means and SE of combinations of bridging types):

- From epithet to hypernym, we did not find a significant difference between left and right dislocation, $b=-0.35, S E=0.20, t(1871.10)=-1.76, p=.079$, but we did find one between left dislocation and canonical; ratings sharply increased with canonical, while they (unexpectedly) slightly decreased with left dislocation, $b=0.74, S E=0.20, t(1868.80)=3.64, p<.001$.

- From epithet + hypernym to set-member there was a significant difference between right and left dislocations, $b=0.54, S E=0.12, t(1869.70)=4.69, p<$ .001; specifically, ratings decreased with right dislocation and increased with left dislocation. No difference was found between left dislocation and canonical, $b=$ $-0.04, S E=0.12, t(1870.20)=-0.36, p=.717$.

- From epithet + hypernym + set-member to necessary part there was again a significant difference between right and left dislocation, $b=0.24, S E=0.08$, $t(1868.80)=3.02, p=.003$, and between left dislocation and canonical, $b=$ -0.23, $S E=0.08, t(1869.50)=-2.77, p=.006$; ratings again decreased with right dislocations and increased with canonical sentences, though they stayed constant with left dislocations.

- Finally, all ratings decreased from epithet + hypernym + set-member + necessary part to optional part, but no significant difference was found between the three constructions.

\section{[TABLE 4]}

\section{Discussion}


The overall higher ratings with left over right dislocation support the findings of Experiment 1. The high ratings of canonical sentences are expected, since canonical constructions are unmarked and thus, by default, generally better rated than noncanonical ones. The absence of a significant difference between left dislocation and canonical sentences confirms that these bridging contexts are particularly suited for left dislocation. As far as the bridging strength hypothesis is concerned, results of Experiment 2 support our hypothesis in that ratings with right dislocation and those with canonical sentences go to opposite directions: With the former, they decrease from the two strongest to the weakest bridging type; with the latter -setting aside the low ratings of optional part- they rise from the weakest to the strongest bridging type. Contrary to our hypothesis, however, ratings with left dislocation do not increase from the strongest to the weakest bridging type.

All in all, the addition of canonical sentences helps us to better understand the participants' behavior. In particular, if we look more closely at the three constructions, we observe some differences with respect to the hypernym bridging type which are worth commenting.

Hypernym's ratings were higher with right dislocations and canonical sentences than with left dislocations. Furthermore, if we compare such ratings to those of the bridging type following hypernym in the scale in (21), namely set-member, we observe that:

- With right dislocations, hypernym was rated higher than set-member.

- With left dislocations, hypernym was rated lower than set-member.

- With canonical sentences, hypernym was rated as high as set-member and necessary part.

The differences just described suggest that Bott's (2007) monotonicity hypothesis may be correct, namely that the downward monotonic relation set-member (e.g., from the cities of Tuscany to Florence) is best associated with left dislocation, whereas the upward monotonic relation of hypernym (e.g., from chickpeas to legumes) is best associated with right dislocation. Therefore, we decided to specifically test such a hypothesis by carrying out a third (and last) acceptability judgment experiment, which we report in the next subsection. 


\section{Experiment 3}

According to Bott's (2007) hypothesis, a right dislocate must be in an upward monotonic anaphoric relation with its antecedent, whereas a left dislocate must be in a downward monotonic or in a non-monotonic one. In Experiments 1 and 2, the setmember bridging type clearly represents a case of downward anaphor; the hypernym bridging type, on the other hand, is clearly upward monotonic. In Experiment 3 we made the hypothesis that the differences between hypernym and set-member described above are a consequence of the monotonic properties of these bridging types.

\section{Method.}

\section{Participants.}

Thirty-six native Catalan speakers were selected for Experiment 3; they had not participated in previous experiments. All participants answered the questionnaire on their linguistic background used in previous experiments, and we discarded 4 candidates who were classified as Spanish language dominant speakers. In conclusion, we considered the data of 32 participants (26 women and 6 men), who ranged between 18 and 29 years (mean age $=20.9$ ).

\section{Design.}

In this experiment we tested four bridging types: two downward monotonic ones and two upward monotonic ones. Downward monotonic items included relations from hypernym to hyponym, (25), and from set to member, (26). Upward monotonic items included relations from hyponym to hypernym, (27), and from member to set, (28). We just provide an example with left dislocation for space constraints:

a. 'After supper, I like liquors.'

b. El whisky escocès, el prenc amb gel. the whisky Scotch it I.drink with ice 'Scotch, I take on the rocks.'

(26) a. 'Last summer, I visited all the cities of Tuscany.'

b. Florència, la vaig recórrer de punta a punta. Florence it I.did go.through from end to end 'I wandered all through Florence.'

a. 'I love Scotch.' 
b. Els licors, els bec després de sopar.

the liquors them I.drink after of supper

'Spirits, I take after supper.'
a. 'I wandered all through Florence.'
b. Les ciutats de la Toscana, finalment les vaig visitar totes. the cities of the Tuscany finally them I.did visit all
'The cities of Tuscany, I eventually visited them all.'

The experiment included 24 experimental items, 12 for each of the 2 bridging conditions (downward vs upward monotonic), as well as 12 fillers.

Procedure.

The same procedure was followed as that described for Experiments 1 and 2 .

\section{Results}

As in Experiments 1 and 2, a statistical analysis based on a linear mixed-effect model was carried out, with ratings as dependent variable and participant and item as random factors. Dislocation type and monotonicity were chosen as independent factors. The conditions of dislocation type were right and left dislocation (the latter coded as the reference category), while those of monotonicity were upward monotonic and downward monotonic (the latter coded as reference category). Mean ratings (and SE) for left and right dislocation globally and for each monotonic context are reported in Table 5.

\section{[TABLE 5]}

Results showed a significant interaction between dislocation type and monotonicity, $b=1.66, S E=0.39, t(342.20)=4.24, p<.001$. Specifically, as Figure 3 clearly illustrates, right dislocation received lower ratings than left dislocation in downward monotonic contexts, while no difference was found between left and right dislocation in upward monotonic contexts.

\section{[FIGURE 3]}

By comparing a model with and a model without the monotonicity factor via a likelihood ratio test, we saw that monotonicity by itself did not have an effect on the model, $\chi^{2}(1)=1,79, p=.181$. A linear model with only dislocation type as independent variable showed that right dislocation was rated worse than left dislocation, $b=$ 
0.33, $S E=0.08, t(341.40)=4.08, p<.001$, in line with previous experiments.

\section{Discussion}

A first observation is that both dislocations receive pretty high ratings ( 7 or more) in both monotonic environments, which suggests that Bott's judgments in (13) and (14) are too strong. As far as the monotonicity hypothesis is concerned, our results support it, but only as a tendency, not as a categorical rule. Indeed, right dislocations are rated better with upward monotonic relations (member-set and hypernym-hyponym) and left dislocations are rated better with downward monotonic ones (set-member and hyponym-hypernym). However, this tendency does not prevent left dislocation from being rated as high as right dislocation in upward monotonic contexts. Such an asymmetry runs against theoretical studies (Vallduví, 1992; Bott, 2007; Brunetti 2009a), which argue that, since a left dislocate in Catalan is a topic selected among a set of alternatives in the context, it must be linked to its antecedent, by definition, via a downward monotonic relation.

This claim is at odds with the relatively high ratings of left dislocations in upward monotonic contexts. One possible explanation to this discrepancy is to assume that the listener always recreates a downward monotonic context between the dislocate and its antecedent. This is basically the account that Bott (2007) (but see also Brunetti, 2006, 2009a) gives to cases where a left dislocated expression is in an answer to a question that contains the same expression, like in the following Catalan example from Bott (2007, p. 113):

Q: 'Any news about Enric?'

A: L'Enric, no l'he vist. the Enric not him-I.have seen 'Enric, I haven't seen.'

The position of the dislocate to the left is not expected, because no alternative set is given to l'Enric in this context. However, the repetition of l'Enric in the answer triggers a contrastive interpretation, according to which the speaker has seen someone else. The reason for such an interpretation is that listeners interpret the presence of the dislocate as an indication that its referent is in a downward monotonic relation 
with some set. In the absence of contextual clues, listeners accommodate the existence of such a set. Cases like (27) or (28), which involve a specific antecedent (Scotch and Florence, respectively) and a more general left dislocate (liquors and the cities of Tuscany, respectively) can be analyzed in a similar way. Listeners accommodate an interpretation such that the dislocate forms a set with other referents to be mentioned in subsequent discourse. For instance, the cities of Tuscany may be interpreted as a member of a set of sets of cities (the cities of Tuscany, the cities of Sicily, the cities of Veneto, etc.), whose relevance becomes clear in subsequent discourse (for instance, if the cities of Tuscany are contrasted with the cities of other regions of Italy). If this analysis is correct, then the relatively high scores of left dislocations in upward monotonic contexts are due to the fact that, even in cases of upward monotonicity, a downward monotonic antecedent is inferred by listeners.

However, since some kind of accommodation must be done in such contexts in order to get the desired interpretation, it is not surprising that scores will still be lower than those given in explicit downward monotonic antecedents. Such an account is also valid, according to Bott, for non-monotonic anaphora, as we already mentioned in Section Monotonicity.

This line of analysis also explains the lower ratings of right dislocation with downward monotonic antecedents, since no similar accommodation process is available in that case. However, this analysis leaves unaccounted the fact that right dislocation is acceptable, albeit not preferred, in both a downward monotonic context (as shown by Experiment 3) and a non-monotonic context, like (12-b) (I saw Modern Times again yesterday. He's amazing, (this) Charlie Chaplin). We leave an explanation for this particular behavior to future research.

Finally, another possible explanation for the special behavior of left dislocation in Experiment 3 has to do with its function introducing a new segment of discourse (by topic shift). Even in an upward monotonic context, left dislocation is licensed if the subsequent discourse is clearly about the new referent introduced by the dislocate. Since no context is given after the target sentence in our stimuli, such an interpretation can be accommodated by the listener/reader, increasing the rating of left dislocates. 


\section{General Discussion and Conclusions}

In this paper we have analyzed the relationship in Catalan between the position of an expression in the sentence (dislocated to the left, to the right, or in situ) and the strength of the anaphoric link between the referent of such an expression and its antecedent. We have tested the hypothesis that right dislocation occurs more naturally in cases of a strong bridging link between the referent and its antecedent, while left dislocation or a canonical position occur more naturally when the bridging link is weaker. Results of the first two acceptability judgment experiments partially support our hypothesis in that a decrease of ratings from the strongest to the weakest bridging type is visible with right dislocation; interestingly, however, the opposite tendency is only visible with canonical sentences but not with left dislocation. The latter construction does not seem to be affected by the bridging strength as much as its rightward counterpart is, which we interpret as a consequence of its prototypical pragmatic functions: topic shifting and contrast. Indeed, if we assume that left dislocation always evokes alternatives (see Brunetti 2009a; López 2009, Villalba, 2000, ch. 2), its high ratings with set-member and necessary part are clearly explained, without having to call upon bridging strength.

The pragmatic functions of left dislocation are also compatible with Bott's (2007) analysis of left dislocation as involving a downward monotonic relationship with an antecedent. Experiment 3, which explicitly tested the monotonicity hypothesis, supports this claim. However, unlike what Bott's analysis seems to suggest, we did not find a clear division of labor between right and left dislocation in upward and downward monotonic contexts respectively, for the latter covers part of the space one would reserve for the former.

Overall, the resultant picture is more complex than previous analyses suggested, and shows that whereas anaphoric strength is a major factor in explaining the distribution of left and right dislocation in Catalan, other variables conspire to blur its effect, mainly the contrastive implicature triggered by left dislocation.

\section{Acknowledgments}

We are grateful to the audience of the workshop "The Meaning of Functional Cat- 
egories in the Nominal Domain" (March 21-22, 2019, Universitat Autònoma de Barcelona), where part of the material in this article was presented. Thanks are also due to two anonymous reviewers and the editor for useful comments, to Sílvia PlanasMorales for helping with the recordings for Experiments 2 and 3, and to Yair Haendler for his precious help with the statistical analysis.

\section{Disclosure statement}

No potential conflict of interest was reported by the author(s).

\section{Funding}

This work was supported by the French National Research Agency (ANR) public grant ANR-10-LABX-0083 and contributes to the IdEx Université de Paris - ANR-18-IDEX0001 (Lisa Brunetti); the research project PGC2018-094029-A-I00 (Spanish State Research Agency (AEI) and the European Regional Development Fund (FEDER, UE)), awarded to the UPF (Laia Mayol); the research Project FFI2017-82547-P (MINECO), awarded to the Center of Linguistic Theory of UAB (Lisa Brunetti and Xavier Villalba) and the grant 2017SGR634 (AGAUR), awarded to the Center of Linguistic Theory of UAB (Xavier Villalba).

\section{ORCID}

Lisa Brunetti https://orcid.org/0000-0001-8515-1550

Laia Mayol https://orcid.org/0000-0001-5386-816X

Xavier Villalba https://orcid.org/0000-0001-6993-976X

\section{References}

Alexopoulou, T., \& Kolliakou, D. (2002). On linkhood, topicalization and clitic left dislocation. Journal of Linguistics, 38(2), 193-245. https://doi.org/10.1017/S0022226702001445

Ariel, M. (2001). Accessibility theory: An overview. In T. Sanders, J. Schilperoord, \& W. Spooren (Eds.), Text representation: Linguistic and psycholinguistic aspects (pp. 29-87). John Benjamins. https://doi.org/10.1075/hcp.8.04ari

Arregi, K. (2014). Clitic left dislocation is contrastive topicalization. In S. Arunacha- 
lam, U. Horesh, E. Kaiser, I. Ross, T. Sánchez, \& A. Williams (Eds.), Proceedings of the 26th Annual Penn Linguistics Colloquium (pp. 1-14). Penn Linguistics Club. Asher, N. (2000). Events, facts, propositions, and evolutive anaphora. In J. Higginbotham, F. Pianesi, \& A. C. Varzi (Eds.), Speaking of events (pp. 123-150). Oxford University Press.

Asher, N., \& Lascarides, A. (1998). Bridging. Journal of Semantics, 15(1), 83-113.

Asher, N., \& Lascarides, A. (2003). Logics of conversation. Cambridge University Press.

Bates, D., Mächler, M., Bolker, B., \& Walker, S. (2015). Fitting linear mixed-effects models using lme4. Journal of Statistical Software, 67(1), 1-48. https://doi.org/10.18637/jss.v067.i01

Birner, B. J., \& Ward, G. (1998). Information status and noncanonical word order in English. John Benjamins. https://doi.org/10.1075/slcs.40

Bott, S. M. (2007). Information structure and discourse modelling (Doctoral thesis, Universitat Pompeu Fabra, Barcelona, Spain). Retrieved from http://hdl.handle.net/10803/7573

Brunetti, L. (2006). Italian background: links, tails, and contrast effects. In B. Gyuris (Ed.) Proceedings of the ninth Symposium on Logic and Language (pp. 45-52). Eőtvős Loránd University.

Brunetti, L. (2009a). On links and tails in Italian. Lingua, 119(5), 756-781. https://doi.org/10.1016/j.lingua.2008.10.005

Brunetti, L. (2009b). On the semantic and contextual factors that determine topic selection in Italian and Spanish. The Linguistic Review, 26(2-3), 261-289. https://doi.org/10.1515/tlir.2009.010

Burkhardt, P. (2006). Inferential bridging relations reveal distinct neural mechanisms: Evidence from event-related brain potentials. Brain and Language, 98(2), 159-168. https://doi.org/10.1016/j.bandl.2006.04.005

Callahan, S. M. (2008). Processing anaphoric constructions: Insights from electrophysiological studies. Journal of Neurolinguistics, 21(3), 231-266. https://doi.org/10.1016/j.jneuroling.2007.10.002

Chafe, W. L. (1976). Givenness, contrastiveness, definiteness, subjects, topics, and 
point of view. In C. Li (Ed.), Subject and topic (pp. 25-55). Academic Press.

Clark, H. H. (1975). Bridging. In B. L. Nash-Webber \& R. Schank (Eds.), Proceedings of the $19^{7} 5$ workshop on theoretical issues in natural language processing (pp. 169-174). Association for Computational Linguistics. https://doi.org/10.3115/980190.980237

Clark, H. H. (1977). Inferences in comprehension. In D. LaBerge \& S. J. Samuels (Eds.), Basic processes in reading: Perception and comprehension (pp. 243-263). Lawrence Erlbaum.

Daneš, F. (Ed.). (1974). Papers on functional sentence perspective. Mouton. https://doi.org/10.1515/9783111676524

Drummond, A. (2016). IbexFarm (Version 0.3.9) [Computer software]. Retrieved from https://spellout.net/ibexfarm/

Firbas, J. (1992). Functional sentence perspective in written and spoken communication. Cambridge University Press.

Forcadell, M. (2016). New prosodic patterns in Catalan: Information status and (de)accentability. Journal of Pragmatics, 97, 1-20. https://doi.org/10.1016/j.pragma.2016.03.007

de la Fuente, I., Hemforth, B., Colonna, S., \& Schimke, S. (2016). The role of syntax, semantics, and pragmatics in pronoun resolution: A cross-linguistic overview. In A. Holler \& K. Suckow (Eds.), Empirical perspectives on anaphora resolution (pp. 11-31). De Gruyter. https://doi.org/10.1515/9783110464108-003

Gardent, C., Manuélian, H., \& Kow, E. (2003). Which bridges for bridging definite descriptions? Proceedings of 4 th International Workshop on Linguistically Interpreted Corpora (pp. 69-76). Association for Computational Linguistics. https://www.aclweb.org/anthology/W03-2410

Gertken, L. M., Amengual, M., \& Birdsong, D. (2014). Assessing language dominance with the Bilingual Language Profile. In P. Leclercq, A. Edmonds, \& H. Hilton (Eds.), Measuring L2 proficiency (pp. 208-225). Multilingual Matters. https://doi.org/10.21832/9781783092291-014

Geurts, B. (2011). Accessibility and anaphora. In K. von Heusinger, C. Maienborn, \& P. Portner (Eds.), Semantics. An international handbook 
of natural language meaning. Volume 2 (pp. 1988-2011). De Gruyter. https://doi.org/10.1515/9783110255072.1988

Givón, T. (1983). Topic continuity in discourse: Introduction. In T. Givón (Ed.), Topic continuity in discourse: A quantitative cross-language study (pp. 5-41). John Benjamins. https://doi.org/10.1075/tsl.3

Grice, H. P. (1975). Logic and conversation. In P. Cole \& J. Morgan (Eds.), Speech acts (pp. 41-58). Academic Press.

Grosz, B. J., \& Ziv, Y. (1998). Centering, global focus, and right dislocation. In M. Walker, A. Joshi, \& E. Prince (Eds.), Centering theory in discourse (pp. 293-307). Clarendon Press.

Haviland, S. E., \& Clark, H. H. (1974). What's new? Acquiring new information as a process in comprehension. Journal of Verbal Learning and Verbal Behavior, 13(5), 512-521. https://doi.org/10.1016/S0022-5371(74)80003-4

Hendriks, H. (2015). Information packaging: From cards to boxes. In T. Galloway \& J. Spence (Eds.), Proceedings of the 6th Semantics and Linguistic Theory Conference (pp. 75-92). Cornell University. https://doi.org/10.3765/salt.v0i0.2765

Hendriks, H., \& Dekker, P. (1995). Links without locations. In P. Dekker \& M. Stokhof (Eds.), Proceedings of the tenth Amsterdam colloquium (pp. 339-358). University of Amsterdam.

Huang, Y. (2000). Discourse anaphora: Four theoretical models. Journal of Pragmatics, 32(2), 151-176. https://doi.org/10.1016/S0378-2166(99)00041-7

Irmer, M. (2011). Bridging inferences: Constraining and resolving underspecification in discourse interpretation. De Gruyter.

Kaiser, E., \& Trueswell, J. C. (2008). Interpreting pronouns and demonstratives in Finnish: Evidence for a form-specific approach to reference resolution. Language and Cognitive Processes, 23(5), 709-748.

Kehler, A. (2002). Coherence, reference, and the theory of grammar. CSLI Publications.

Kleiber, G. (2001). L'anaphore associative. Presses Universitaires de France.

Lambrecht, K. (1996). Information structure and sentence form. Cambridge University Press. 
López, L. (2009). A derivational syntax for information structure. Oxford University Press. https://doi.org/10.1093/acprof:oso/9780199557400.001.0001

Manetta, E. (2007). Unexpected left dislocation: An English corpus study. Journal of Pragmatics, 39(5), 1029-1035. https://doi.org/10.1016/j.pragma.2007.01.003

Mann, W. C., \& Thompson, S. A. (1988). Rhetorical structure theory: Toward a functional theory of text organization. Text, 8(3), 243-281. https://doi.org/10.1515/text.1.1988.8.3.243

Matsui, T. (1998). Pragmatic criteria for reference assignment: A Relevance-theoretic account of the acceptability of bridging. Pragmatics \& Cognition, 6(1-2), 47-97. https://doi.org/10.1075/pc.6.1-2.06mat

Matsui, T. (2000). Bridging and relevance. John Benjamins.

Mayol, L. (2007). Right-dislocation in Catalan: Its discourse function and counterparts in English. Languages in Contrast, $7(2)$, 203-219. https://doi.org/10.1075/lic.7.2.07may

Mayol, L., \& Villalba, X. (2018). Bridging and dislocation in Catalan. In L. Repetti \& F. Ordóñez (Eds.), Romance languages and linguistic theory 14. Selected papers from the 46th Linguistics Symposium on Romance Languages (pp. 201-213). John Benjamins. https://doi.org/10.1075/rllt.14.11may

Mitkov, R. (2012). Anaphora resolution. In R. Mitkov (Ed.), The Oxford handbook of computational linguistics (pp. 266-283). Oxford University Press. https://doi.org/10.1093/oxfordhb/9780199276349.013.0014

Partee, B. H., Ter Meulen, A., \& Wall, R. E. (1987). Mathematical methods in linguistics. Springer.

Poesio, M. (2016). Linguistic and cognitive evidence about anaphora. In M. Poesio, R. Stuckardt, \& Y. Versley (Eds.), Anaphora resolution. Algorithms, resources and applications (pp. 23-54). Springer. https://doi.org/10.1007/978-3-662-47909-4-2

Prince, E. F. (1998). On the limits of syntax, with reference to left-dislocation and topicalization. In P. Culicover \& L. McNally (Eds.), The limits of syntax. (pp. 281302). Brill. https://doi.org/10.1163/9789004373167-011

R Core Team. (2017). R: A language and environment for statistical computing [Computer software]. Retrieved from https://www.r-project.org/ 
Reinhart, T. (1983). Anaphora and semantic interpretation. Routledge. https://doi.org/10.4324/9781315536965

Schwarz-Friesel, M. (2007). Indirect anaphora in text. In M. Schwarz-Friesel, M. Consten, \& M. Knees (Eds.), Anaphors in text: Cognitive, formal and applied approaches to anaphoric reference (pp. 3-20). John Benjamins. https://doi.org/10.1075/slcs.86.04sch

Singer, M. (2012). Inference processing in discourse comprehension. In M. G. Gaskell, G. Altmann, \& P. Bloom (Eds.), The Oxford handbook of psycholinguistics (pp. 343-359). Oxford University Press. https://doi.org/10.1093/oxfordhb/9780198568971.013.0020

Singer, M., \& Halldorson, M. (1996). Constructing and validating motive bridging inferences. Cognitive Psychology, 30(1), 1-38. https://doi.org/10.1006/cogp.1996.0001

Tomioka, S. (2010). Contrastive topics operate on speech acts. In M. Zimmermann \& C. Féry (Eds.), Information structure: Theoretical, typological, and experimental perspectives (pp. 115-138). Oxford University Press. https://doi.org/10.1093/acprof:oso/9780199570959.003.0006

Umbach, C. (2003). Anaphoric restriction of alternative sets: on the role of bridging antecedents. In M. Weisgerber (Ed.), Proceedings of Sinn und Bedeutung 7 (pp. 310-323). Universität Konstanz.

Vallduví, E. (1992). The informational component. Garland.

Vasishth, S., \& Broe, M. (2011). Bivariate statistics and linear models. In S. Vasishth \& M. Broe (Eds.), The foundations of statistics: A simulation-based approach (pp. 127-143). Springer. https://doi.org/10.1007/978-3-642-16313-5-6

Venables, W. N., \& Ripley, B. D. (2013). Modern applied statistics with S. Springer.

Villalba, X. (2000). The syntax of sentence periphery (Doctoral thesis, Universitat Autònoma de Barcelona, Barcelona, Spain). Retrieved from http://hdl.handle.net/10803/4838

Villalba, X., \& Mayol, L. (2013). Right-dislocation in Catalan: Tails, polarity and activation. International Review of Pragmatics, 5(1), 87-117. https://doi.org/10.1163/18773109-13050104 
Ward, G., \& Birner, B. J. (2008a). Discourse and information structure. In D. Schiffrin, D. Tannen, \& H. E. Hamilton (Eds.), The handbook of discourse analysis (pp. 119137). Wiley and Sons. https://doi.org/10.1002/9780470753460.ch7

Ward, G., \& Birner, B. J. (2008b). Information structure and non-canonical syntax. In L. Horn \& G. Ward (Eds.), The handbook of pragmatics (pp. 152-174). Wiley and Sons. https://doi.org/10.1002/9780470756959.ch7

Ward, G., \& Prince, E. F. (1991). On the topicalization of indefinite NPs. Journal of Pragmatics, 16(2), 167-177. https://doi.org/10.1016/0378-2166(91)90079-D

Webber, B., Joshi, A., Stone, M., \& Knott, A. (2003). Anaphora and discourse structure. Computational Linguistics, 29(4), 545-587. https://doi.org/10.1162/089120103322753347

Ziv, Y. (1994). Left and right dislocations: Discourse functions and anaphora. Journal of Pragmatics, 22(6), 629-645. https://doi.org/10.1016/0378-2166(94)90033-7

\section{Figures}

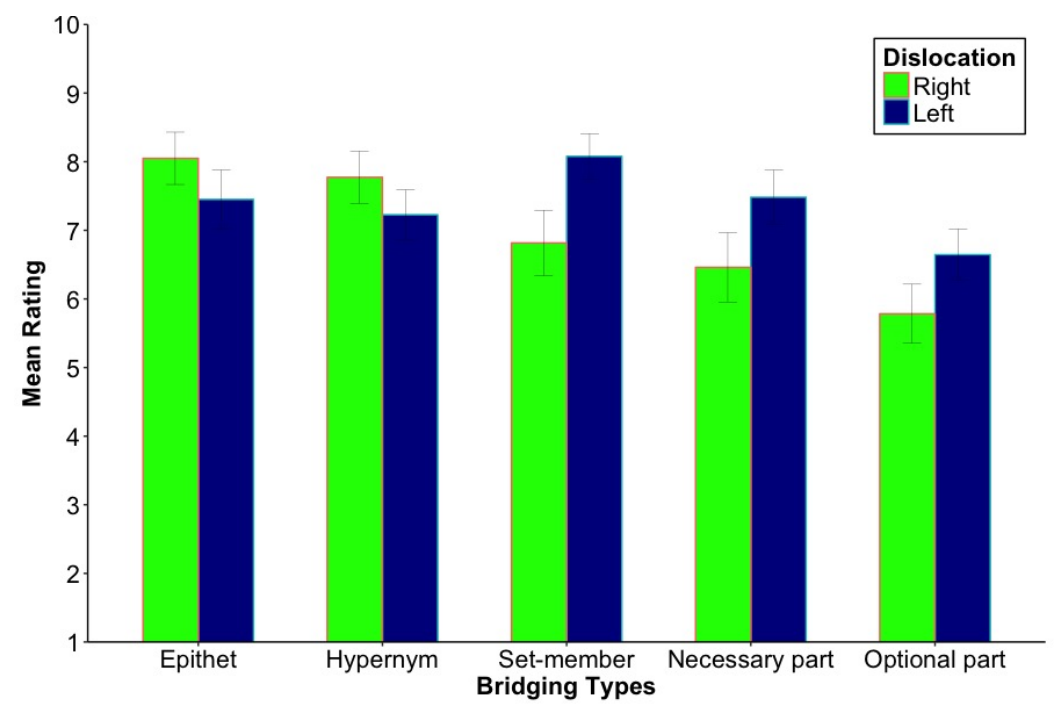

Figure 1. Ratings of left and right dislocation across bridging types in Experiment 1. Error bars attached to each column represent standard errors. 


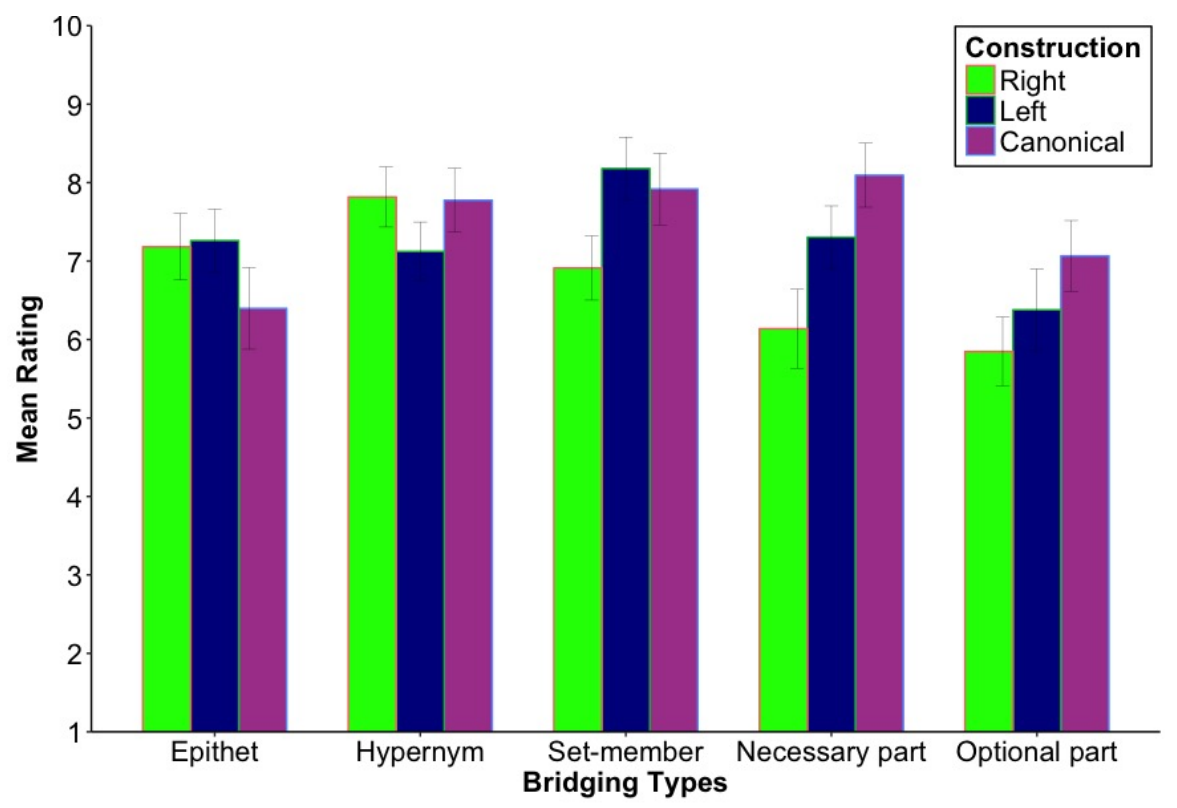

Figure 2. Ratings of left dislocation, right dislocation, and canonical sentence across bridging types in Experiment 2. Error bars attached to each column represent standard errors.

Table 1.

Mean ratings (and SE) by bridging types and dislocation in Experiment 1

\begin{tabular}{lrr}
\hline Bridging Type & Right dislocation & Left dislocation \\
\hline All & $6.98(0.10)$ & $7.37(0.09)$ \\
Epithet & $8.05(0.19)$ & $7.44(0.21)$ \\
Hypernym & $7.79(0.19)$ & $7.21(0.20)$ \\
Set-member & $6.88(0.22)$ & $8.08(0.18)$ \\
Necessary Part & $6.44(0.22)$ & $7.49(0.21)$ \\
Optional Part & $5.76(0.23)$ & $6.65(0.22)$ \\
\hline
\end{tabular}

Word count: 10237 


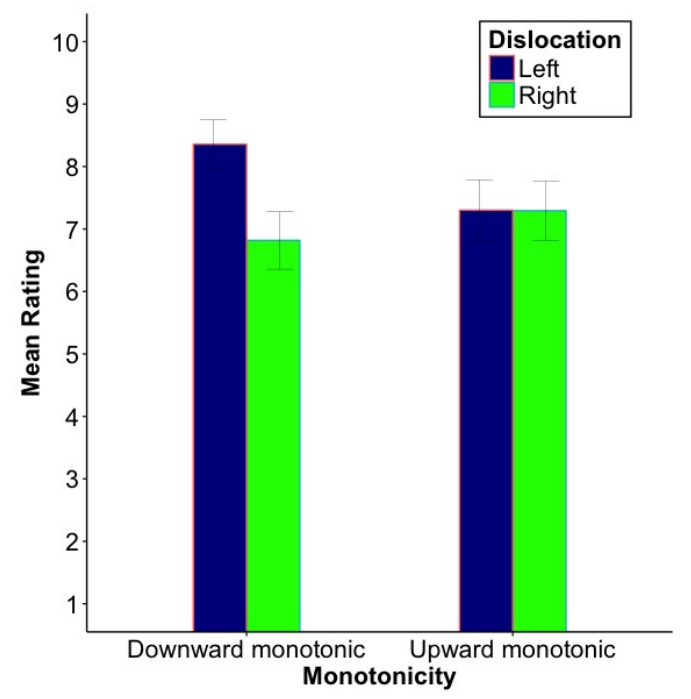

Figure 3. Ratings for left and right dislocations depending on the monotonic context in Experiment 3. Error bars attached to each column represent standard errors.

Table 2.

Mean ratings (and SE) by combinations of bridging types and dislocation in Experiment 1

\begin{tabular}{lrr}
\hline Bridging Type & Right dislocation & Left dislocation \\
\hline Epithet + Hypernym & $7.92(0.13)$ & $7.33(0.15)$ \\
Epithet + Hypernym + Set-member & $7.55(0.12)$ & $7.58(0.12)$ \\
Epithet + Hypernym + Set-member + Necessary Part & $7.28(0.11)$ & $7.55(0.10)$ \\
\hline
\end{tabular}

Table 3.

Mean ratings (and SE) by bridging types and construction in Experiment 2

\begin{tabular}{lrrr}
\hline Bridging Type & Right & Left & Canonical \\
\hline All & $6.76(0.11)$ & $7.27(0.11)$ & $7.50(0.11)$ \\
Epithet & $7.13(0.24)$ & $7.22(0.24)$ & $6.39(0.27)$ \\
Hypernym & $7.82(0.21)$ & $7.16(0.23)$ & $7.79(0.21)$ \\
Set-member & $6.95(0.24)$ & $8.15(0.20)$ & $7.98(0.22)$ \\
Necessary Part & $6.16(2.46)$ & $7.35(0.22)$ & $8.13(0.20)$ \\
Optional Part & $5.83(2.45)$ & $6.45(0.26)$ & $7.18(0.24)$ \\
\hline
\end{tabular}

Table 4.

Mean ratings (and SE) for combinations of bridging types and construction in Experiment 2

\begin{tabular}{lrrr}
\hline Bridging Type & Right & Left & Canonical \\
\hline Epithet + Hypernym & $7.47(1.59)$ & $7.19(1.64)$ & $7.10(0.18)$ \\
Epithet + Hypernym + Set-member & $7.30(1.34)$ & $7.52(1.30)$ & $7.40(1.40)$ \\
Epithet + Hypernym + Set-member + Necessary Part & $7.01(0.12)$ & $7.47(0.11)$ & $7.58(0.12)$ \\
\hline
\end{tabular}

Table 5.

Means (and SE) by monotonicity and dislocation types in Experiment 3.

\begin{tabular}{lrr}
\hline Monotonicity Type & Right Dislocation & Left Dislocation \\
\hline All & $7.03(0.18)$ & $7.84(0.18)$ \\
Upward Monotonic & $7.29(0.26)$ & $7.33(0.26)$ \\
Downward Monotonic & $6.77(0.24)$ & $8.34(0.23)$ \\
\hline
\end{tabular}

